\title{
Avaliação da \\ Adsorção de Cobre(II) \\ em Esferas de Quitosana \\ e Quitosana Reticulada
}

\section{Anderson J. L. Catão \& Roberta Signini}

A adsorção de íons cobre (II), em esferas de quitosana e esferas de quitosana reticulada, foi investigada. A caracterização da quitosana e da quitosana reticulada com glutaraldeído foi realizada por espectroscopia de absorção na região do infravermelho e através da determinação do grau de desacetilação (GD). Os dados experimentais, obtidos por espectrofotometria de absorção atômica, foram ajustados pelos modelos de Langmuir e Freundlich. O modelo que melhor ajustou os dados experimentais foi o modelo de Freundlich. A isoterma de Langmuir mostrou uma capacidade máxima de $18,50 \mathrm{mg} \mathrm{g}^{-1}$ para as esferas sem modificação e $14,02 \mathrm{mg} \mathrm{g}^{-1}$ para as esferas modificadas.

Palavras-Chave: quitosana; adsorção; cobre(II).

The adsorption of copper (II) by chitosan spheres and modified chitosan spheres was investigated. The spheres were characterized by determination of DA (degree of acetylation) infrared spectroscopy. The adsorption's experiments were analyzed by atomic absorption spectrophotometer, quantifying the initial and equilibrium concentrations of copper(II). The data were fitted by Langmuir and Freundlich's models. The model that best fit the experimental data for both the chitosan spheres and intercrossed chitosan spheres was the Freundlich's model. The Langmuir isotherm showed a maximum capacity of $18.50 \mathrm{mg} \mathrm{g}^{-1}$ for chitosan spheres and $14.02 \mathrm{mgg}^{-1}$ for the modified spheres.

Keywords: chitosan; adsorption; copper(II). 


\section{Introdução}

Diversas técnicas são usadas para se tratar efluentes contaminados. Muitas delas dependem do contaminante. Quando esse é um composto ou substância não biodegradável, muitos métodos falham parcial ou totalmente, visto que grande parte desses produtos são danosos mesmo em baixas concentrações, como é o caso dos metais tóxicos, cujo poder acumulativo na cadeia alimentar é bem conhecido. Esse último fato torna algumas técnicas, como a precipitação, ineficazes ${ }^{1,2}$. Nesse contexto, surge o processo de separação por adsorção, que tem a vantagem de ser operante, mesmo em baixas concentrações do soluto (poluente), além de produzir baixa quantidade de resíduos; de ter a possibilidade, relativamente fácil, de recuperação do adsorvente (separação do adsorvato) e de ser menos dispendioso financeiramente, principalmente, quando a adsorção é feita em um biomaterial, tornando o processo ainda mais interessante economica e ecologicamente ${ }^{3-5}$.

Dentre os vários biossorventes tem se destacado o produto desacetilado do polímero quitina, a quitosana (Figura 1). A quitosana é um biopolímero, de origem animal ou fúngica, com comprovada capacidade em formar complexo de metais de transição $0^{6,7}$. Quimicamente, a quitosana é o poli[ $[\beta-(1 \rightarrow 4)-2-$ amino-2-desoxi-D-glucopiranose ${ }^{7}$. Dentre os íons metálicos, efetivamente captados pela quitosana, estão: cobre(II), níquel(II), chumbo(II), tório(IV), cromo(III), mercúrio(II) e urânio(VI) - na forma do íon uranilo -, sendo este apenas alguns exemplos ${ }^{8-14}$.

Quitosana é um poliaminossacarídeo catiônico

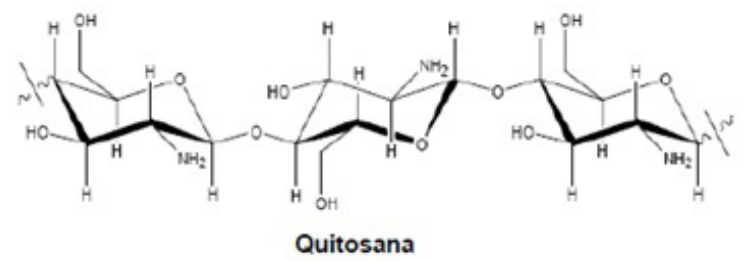

Figura 1. Representação estrutural planar da quitosana
$(\mathrm{pKa}=6,5)$, produto da desacetilação da quitina (polímero, encontrada, principalmente, nas cascas e carapaças de crustáceos). Apesar de ser encontrada naturalmente em alguns fungos, a maior parte da quitosana que se utiliza é derivada do tratamento básico da quitina ${ }^{6}$. Em vista do interesse econômico, a quitosana tem a vantagem de ser um derivado do segundo biopolímero mais abundante na natureza, a quitina, que perde apenas para a celulose em termos de quantidade. A biocompatibilidade, biodegradabilidade e o perfil atóxico fazem da quitosana um dos biomateriais mais interessantes para aplicações industriais e tecnológicas ${ }^{15}$.

Em vista de interesses práticos, melhoramentos químicos ou enzimáticos podem ser feitos na quitosana para ressaltar uma propriedade ou para integrar uma nova. O polímero quitosana em sua forma simples está restrito a uma faixa de $\mathrm{pH}$ de fato neutro e básico, pois nessa faixa a quitosana é insolúvel. A solubilidade da quitosana em meios polares com valores baixos de pH é consequência dos grupos amino protonáveis presentes na cadeia polimérica. Assim sendo, o impedimento, a desativação dos grupos amino funcionais provoca a insolubilização do material em ampla faixas de $\mathrm{pH}^{16}$. Desta forma, o problema de solubilidade pode ser contornado quando se faz uma reação que provoque a reticulação das cadeias de quitosana ${ }^{6}$. $\mathrm{O}$ agente reticulante mais comum é o glutaraldeído $\left(\mathrm{C}_{5} \mathrm{H}_{8} \mathrm{O}_{2}\right)$. O 1,5-pentanodial já é extensamente usado na área biológica como fixador de tecidos, na imobilização de proteínas e na estabilização de matrizes colagênicas. Sua aplicação está associada à sua alta reatividade com grupos amino para a formação de bases de Schiff ${ }^{17}$. A ligação entre o glutaraldeído é tão forte que resiste a extremos de temperatura e $\mathrm{pH}$. No caso da quitosana, a reação com glutaraldeído provoca a formação de ligações cruzadas entre as cadeias poliméricas, permite que o novo material tenha sua solubilidade diminuída, ao dificultar a ação do solvente 9 . Na Figura 2, é representada a reticulação da quitosana com glutaraldeído. 


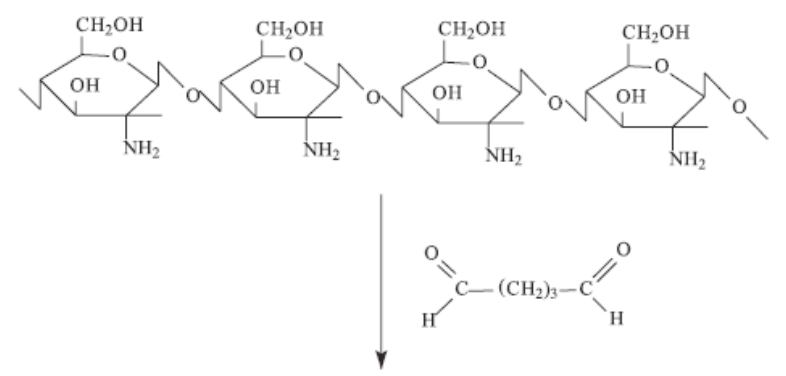

\section{Metodologia}

A quitosana utilizada foi a forma purificada (forma neutra) da quitosana comercial (Polymar) 22,23 .

As esferas de quitosana foram preparadas a partir do gotejamento manual de uma solução de quitosana em ácido acético 5\% (V/V), com o auxílio de uma seringa, a uma solução de hidróxido de sódio 2,5 molL ${ }^{-1}$, sob agitação branda.

Parte das esferas, ainda úmidas, foram submetidas à reação com glutaraldeído, numa razão de $20 \mathrm{mLg}^{-1}$ de quitosana. A reticulação procedeu-se por 15 minutos, cessando-se com abundante lavagem com água, sendo a água de lavagem testada com Reagente de Feder ${ }^{24}$, até total ausência de aldeídos.

A caracterização da quitosana foi feita por meio de dois métodos: Titulação potenciométrica (para a determinação do grau de acetilação) e espectroscopia de absorção na região do infravermelho médio (para a análise das principais bandas). A análise espectroscópica na região do infravermelho médio foi realizada no espectrofotometro Frontier (FT-IR/ $M I D / N E A R / N I R)$ da Perkin Elmer.

O ensaio de tempo de equilíbrio das esferas de quitosana e esferas de quitosana reticulada foi feito através da suspensão de $50 \mathrm{mg}$ de esferas em uma solução de concentração $100 \mathrm{mg} \mathrm{L}^{-1}$ de íons $\mathrm{Cu}(\mathrm{II})$ e do monitoramento da condutividade durante o contato. O monitoramento foi feito, usando o condutivímetro digital $C D-860$ da Instrutherm.

O estudo de adsorção foi realizado mediante suspensão de $50 \mathrm{mg}$ das esferas em $25 \mathrm{~mL}$ de cada uma das soluções de $\mathrm{Cu}(\mathrm{II})$ preparadas a priori. As concentrações das soluções eram de 20, 35, 50, 60, 70, 80, 90 e $100 \mathrm{mg} \mathrm{L}^{-1}$ de $\mathrm{Cu}(\mathrm{II})$, e o pH obtido para estas soluções foi entre 5 e 6 . Essas soluções foram mantidas em banho-maria termostatizado (25 ${ }^{\circ} \mathrm{C} \pm 0,5{ }^{\circ} \mathrm{C}$ ) com agitação pendular até atingir o tempo de equilíbrio. Atingido o equilíbrio, as esferas foram separadas por filtração e o sobrenadante, após diluição adequada, guardado para análise por espectrofotometria de absorção atômica. O espectrofotômetro de absorção atômica utilizado foi o AAnalyst400 da Perkin Elmer. 


\section{Resultados e Discussão}

Os rendimentos da produção das esferas de quitosana e esferas de quitosana entrecruzada foram de $85 \%$ e $90 \%$, respectivamente. O diâmetro médio das esferas produzidas (Figura 3 ) foi de $(1197,89 \pm 132,59) \mu \mathrm{m}$.

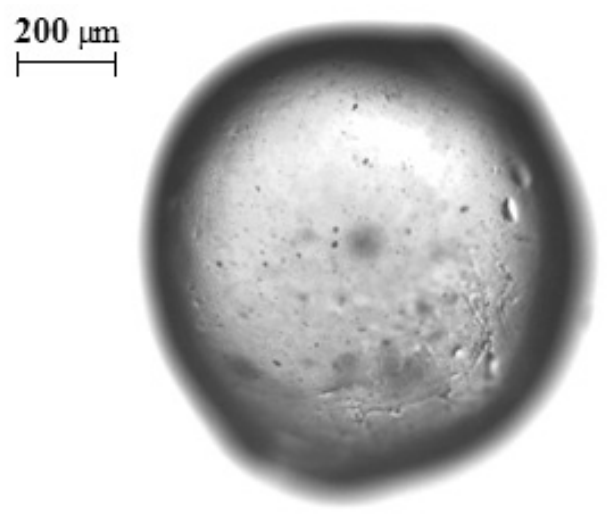

\section{Esfera de quitosana}

Figura 3. Microscopia ótica de uma esfera de quitosana com aumento de $10 \mathrm{x}$

O grau de acetilação da quitosana foi de $26,2 \% \pm$ $0,97 \%$. A reticulação é confirmada pela alteração da cor das esferas, acompanhada pela insolubilização das esferas em meio ácido que é representada por uma curva potenciométrica com apenas um ponto de inflexão, diferentemente da curva de titulação da quitosana que possui dois pontos de inflexão. Quando úmidas, as esferas apresentam uma coloração amarelo fosco e, quando secas, uma coloração avermelhada. Ocorre também alteração na textura das esferas enquanto úmidas. Com a adição do glutaraldeído as esferas, antes macias e parcialmente flexíveis, tornaram-se duras e quebradiças. Tal fato indica uma alteração na estrutura do enovelamento das moléculas, de forma a modificar as propriedades mecânicas ${ }^{6,25}$.

Os espectros de absorção na região do infravermelho dos dois materiais, quitosana e quitosana reticulada, são muito semelhantes com bandas comuns nas regiões de 3500-3300, 2923, 1649, 1596, 1421, 1382, 1323 e $1080 \mathrm{~cm}^{-1}$ (Figura 4). As principais diferenças entre os dois espectros (Figura 4) estão na intensidade da banda que ocorre na região de $1596 \mathrm{~cm}^{-1}$, em relação à banda que ocorre na região de $1650 \mathrm{~cm}^{-1}$, a qual aumenta sua intensidade no espectro de quitosana reticulada, sendo relacionada ao grupo imino (azometino) que corresponde, no espectro de infravermelho, à região de $1689-1471 \mathrm{~cm}^{-}$ 1, podendo estar sobreposto à banda de amida II26, o que explica o aumento na intensidade da banda em $1650 \mathrm{~cm}^{-1}$ quando comparada àquele em $1596^{\mathrm{cm}-1}$. Outra diferença é o aumento da intensidade da banda na região de $2883 \mathrm{~cm}^{-1}$ que corresponde às vibrações axiais do grupamento $\mathrm{C}-\mathrm{H}$, possivelmente, da molécula adicionada (glutaraldeído) que se encontra ligando as cadeias poliméricas.

O tempo de equilíbrio encontrado foi de 6 horas para as esferas de quitosana e de 72 horas para as esferas de quitosana reticulada. A Figura 5 representa os gráficos de Condutividade versus tempo, explanando o tempo de equilíbrio encontrado.

A análise de espectrofotometria de absorção atômica revelou máximo de remoção de $82,09 \%$ para as esferas de quitosana e máximo de $21,72 \%$ para as esferas de quitosana reticulada. Goy, Assis e Campana-Filho ${ }^{27}$ estudaram a adsorção de íons cobre(II) em esferas de quitosana e quitosana reticulada com glutaraldeído, a uma

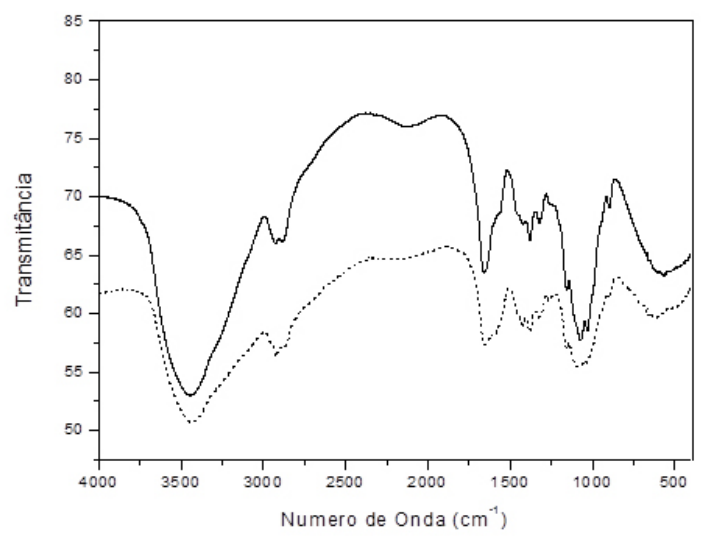

Figura 4. Espectro de absorção na região do infravermelho para a quitosana (......) e quitosana reticulada ( 

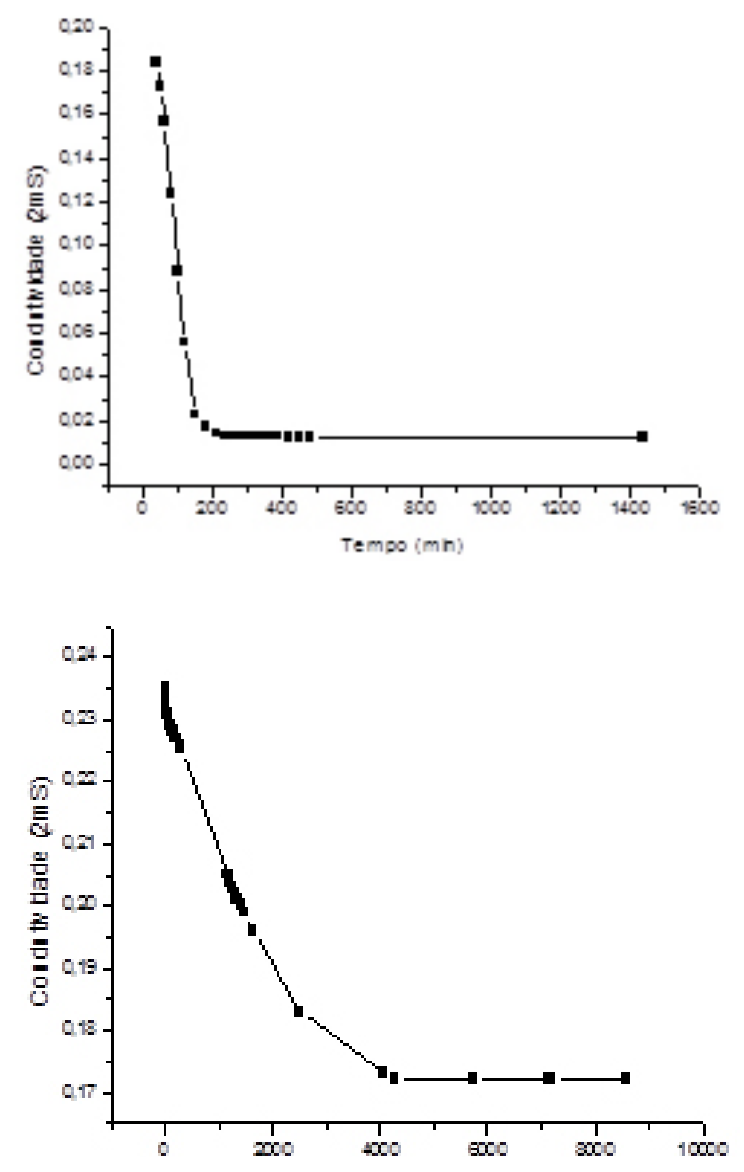

Figura 5. Gráficos de Condutividade x Tempo para determinação do tempo de equilíbrio: (a) esferas de quitosana e (b) esferas de quitosana reticulada.

temperatura média de $25^{\circ} \mathrm{C}$, obtidas de modo semelhante às deste trabalho. As esferas de quitosana com diâmetro médio de $800 \mu \mathrm{m}$ removeram cerca de $43 \%$ de íons $\mathrm{Cu}$ (II) de uma solução de contendo aproximadamente $10 \mathrm{mg}$ de $\mathrm{Cu}(\mathrm{II})$, enquanto que para as esferas de quitosana reticulada, a remoção de $\mathrm{Cu}(\mathrm{II})$ foi de $23 \%$. A diferença de resultados obtidos neste trabalho e no trabalho de Goy, Assis e Campana-Filho ${ }^{27}$ pode estar relacionada ao grau de acetilação, massa molecular da quitosana e heterogeneidade da cadeia polimérica. Tais fatores contribuem para as características da quitosana que estão inseparavelmente ligadas ao processo de adsorção.

Apesar das diferenças observadas neste trabalho e no trabalho de Goy, Assis e Campana-Filho ${ }^{27}$, percebe-se uma semelhança em relação à adsorção dos íons $\mathrm{Cu}$ (II) em esferas de quitosana e esferas de quitosana reticulada: em ambos os estudos, o material reticulado tem a capacidade de adsorção reduzida em relação ao material sem reticulação. Tal fato pode estar relacionado com a razão molar entre grupos aldeído, do agente reticulante, e grupos amino, da quitosana, utilizada para realizar a reação de reticulação.

Koyama e Taniguchi ${ }^{28}$ investigaram diferentes proporções de grupos amino e grupos aldeído ($\mathrm{NH}_{2}$ /-CHO) na realização da reação de reticulação da quitosana. Verificaram que essa proporção está diretamente relacionada com a capacidade de adsorção da quitosana reticulada. Demonstraram que a razão amino/aldeído de 1/0,7 foi a que mais elevou a capacidade de adsorção da quitosana por íons cobre(II), adsorvendo $96 \%$ deste íons em solução. Esse fato pode estar relacionado ao aumento da hidrofilicidade do material e quebra parcial da estrutura cristalina da quitosana, ocasionada pela reação com glutaraldeído, o que permite uma maior acessibilidade aos grupos quelantes da quitosana. Constataram também que algumas proporções podem provocar a redução da capacidade de adsorção, sendo esta atribuída ao aumento da hidrofobicidade do novo material e à formação de bases de Schiff (inviabilizando grupos amino, responsáveis pela adsorção).

Neste estudo, foram empregadas as isotermas de Langmuir e Freundlich para se tratar os dados experimentais. A isoterma de Langmuir prevê que a adsorção (recobrimento) ocorra em apenas uma camada molecular (monocamada), sendo que os sítios de adsorção são considerados uniformes e as moléculas adsorvidas não interagem com os sítios ou moléculas vizinhas ${ }^{20,21}$. Assim sendo, a construção da Isoterma de Langmuir (equação 1) se faz, a partir de um gráfico $\mathrm{C}_{\mathrm{eq}}$ /q versus $\mathrm{C}_{\mathrm{eq}}$ (Figura 6). A linearização dos dados,

$$
\frac{C_{e q}}{q}=\frac{1}{K_{L} \times q_{\max }}+\frac{C_{e q}}{q_{\max }}
$$


regressão linear, origina uma equação da reta, na qual é possível determinar as constantes de Langmuir $\left(\mathrm{K}_{\mathrm{L}}\right.$ e $\left.\mathrm{q}_{\text {máx }}\right)$, sendo: Cqe é a concentração no equilíbrio $\left(\mathrm{mg} \mathrm{L}^{-1}\right) ; \mathrm{q}$ é a quantidade do metal adsorvido $\left(\mathrm{mgg}^{-1}\right)$; qmax é a quantidade máxima de metal adsorvido $\left(\mathrm{mg} \mathrm{g}^{-1}\right) ; \mathrm{K}_{\mathrm{L}}$ é a constante de Langmuir $\left(\mathrm{L} \mathrm{mg}^{-1}\right)$.

A isoterma de Freundlich ocorre geralmente em multicamadas diferentemente da monocamada exigida pela isoterma de Langmuir, sendo a primeira uma derivação da segunda, na qual se modifica a hipótese de que todos os sítios são equivalentes. A construção

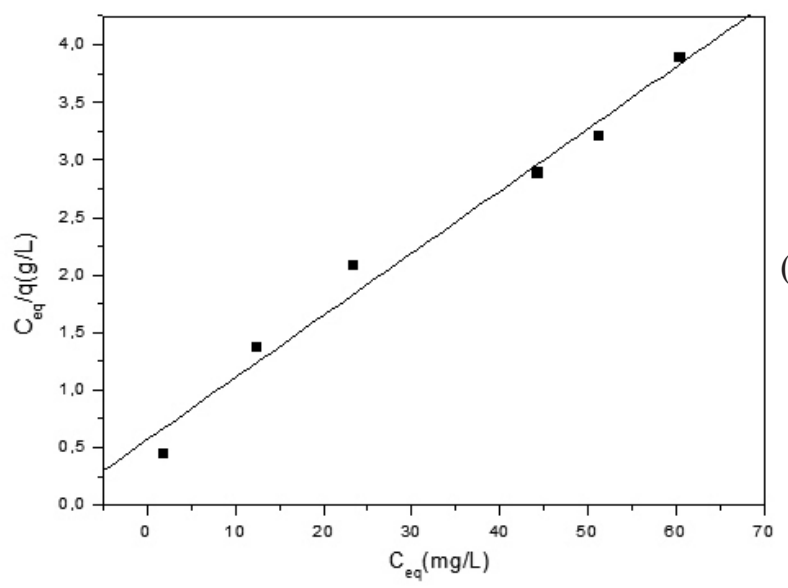

$$
\log q=\log K_{F}+\frac{1}{n} \times \log C_{e}
$$

da Isoterma de Freundich (equação 2) se faz a partir da linearização de um gráfico $\log q$ versus $\log \mathrm{C}_{\mathrm{eq}}$ (Figura 7) sendo: Cqe é a concentração no equilíbrio $\left(\mathrm{mgL}^{-1}\right)$;q é a quantidade do metal adsorvido $\left(\mathrm{mg} \mathrm{g}^{-1}\right) ; 1 / \mathrm{n}$ é uma constante adimensional relacionada com a intensidade da

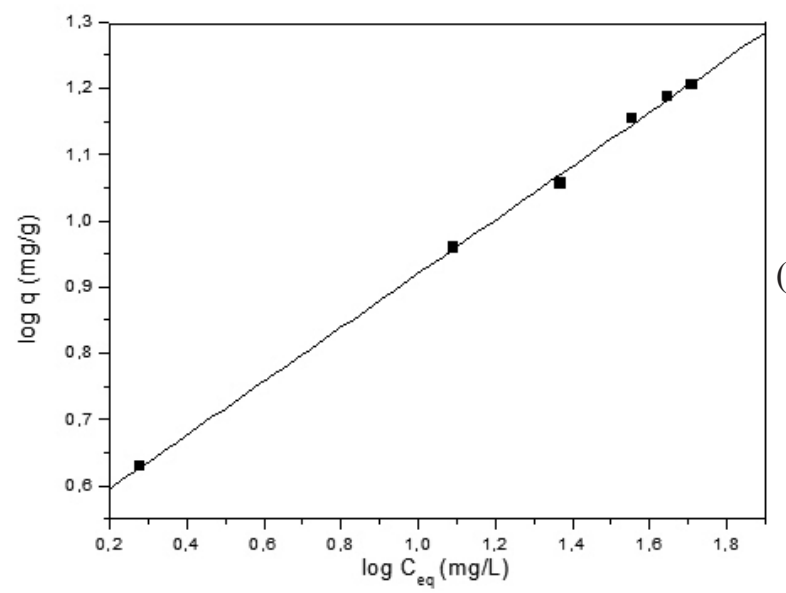

Figura 6. Linearização da isoterma de Adsorção de Langmüir para (a) as esferas de quitosana (a) esferas de quitosana reticulada.
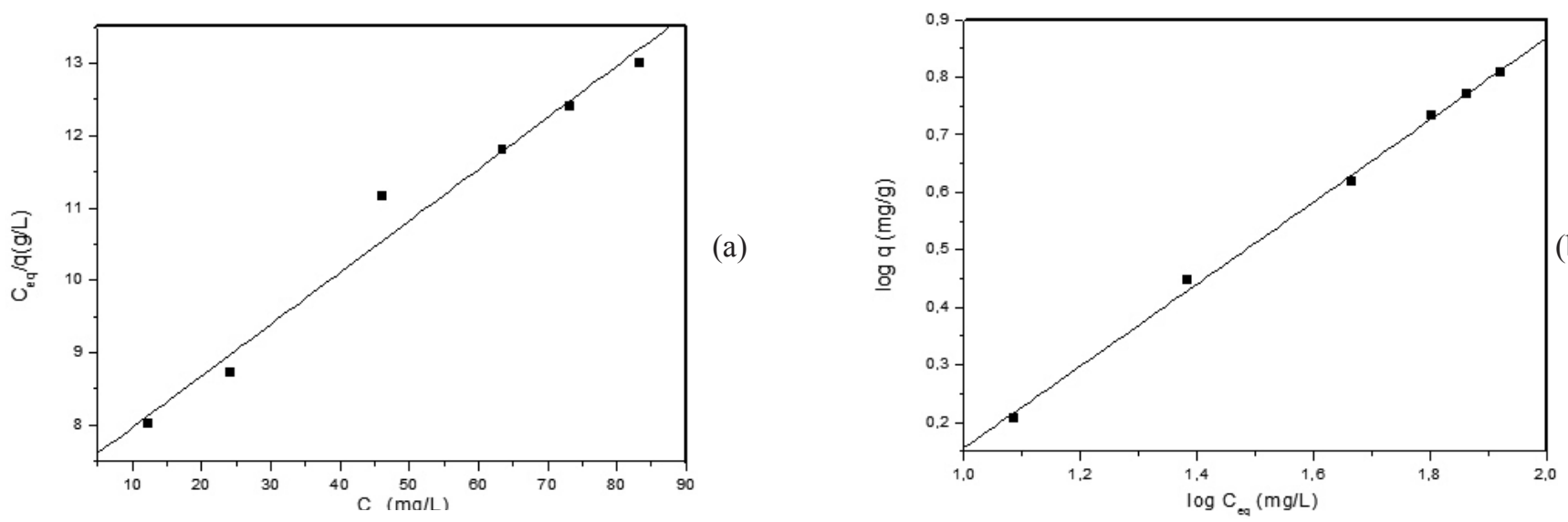

Figura 7. Linearização da isoterma de Adsorção de Freunlich para (a) as esferas de quitosana (a) esferas de quitosana reticulada. 
adsorção, também conhecido como fator de linearidade; $\mathrm{K}_{\mathrm{F}}$ é a constante de Freundlich.

Os resultados do estudo de adsorção de íons cobre(II), aplicando os modelos matemáticos de Langmuir e de Freundlich ${ }^{20,21}$, estão apresentados na Tabela 1. Em ambos os casos, o modelo que melhor ajustou os dados experimentais foi o modelo de Freundlich, resultando em valores de coeficiente de correlação de 0,99837 , para as esferas de quitosana, e de 0,99703, para as esferas de quitosana reticulada. Como os dados são melhores ajustados isotermicamente pelo modelo de Freundlich, pressupõe-se que a adsorçãode íons $\mathrm{Cu}$ (II) pelas esferas quitosana e esferas de quitosana reticulada não é restrita a uma camada (monocamada) de adsorção, ou seja, acontece em multicamadas (superfície heterogênea) ${ }^{20,21}$.

Pode-se analisar o modelo de Langmuir, a partir das constantes $\mathrm{K}_{\mathrm{L}}$ e $\mathrm{q}_{\max }$, dados pelos coeficientes angular $\mathrm{e}$ linear da equação da reta (Isoterma de Langmuir), estando essas constantes relacionadas com a energia da adsorção e a capacidade de adsorção máxima. Existe ainda outro parâmetro, $\mathrm{R}_{\mathrm{L}}$, chamado parâmetro de equilíbrio, uma constante adimensional que indica se a adsorção é ou não favorável. Para valores entre 0 e 1 , a adsorção é considerada favorável ${ }^{29}$. A constante $\mathrm{R}_{\mathrm{L}}$ é definida pela equação 3 ,

$$
R_{L}=\frac{1}{\left(1+K_{L} \times C_{0}\right)}
$$

sendo: $\mathrm{R}_{\mathrm{L}} \mathrm{o}$ parâmetro de equilíbrio; $\mathrm{K}_{\mathrm{L}}$ a constante de Langmuir $\left(\mathrm{Lmg}^{-1}\right) ; \mathrm{C}_{0}$ a concentração inicial mais alta do metal $\left(\mathrm{mgL}^{-1}\right)$.

A partir do parâmetro de equilíbrio $\left(\mathrm{R}_{\mathrm{L}}\right)$, pode-se observar que tanto para a adsorção de $\mathrm{Cu}(\mathrm{II})$ em esferas de quitosana e esferas reticuladas, o processo de adsorção é favorável, pois, nos dois casos, o valor de $\mathrm{R}_{\mathrm{L}}$ é menor que 1. Tal observação também é constatada pelos valores de $\mathrm{n}$ que, em ambos os valores de n, ficaram entre 1 e 10, confirmando que o processo de adsorção é favorável ${ }^{30}$.

A partir da constante de Langmuir, é possível também calcular o calor de adsorção $(\Delta \mathrm{H})^{31}$ pela aproximação dada pela equação 4 ,

$$
\Delta \mathrm{H}=-\mathrm{R} \times \mathrm{T} \times \log \mathrm{K}_{\mathrm{L}}
$$

sendo: $\Delta \mathrm{H}$ o calor de adsorção; $\mathrm{R}$ a constante universal dos gases $\left(8,314 \mathrm{Jmol}^{-1} \mathrm{~K}^{-1}\right)$; $\mathrm{T}$ a temperatura em kelvin (298 K).

O processo de adsorção de íons cobre(II) pelas esferas de quitosana e esferas de quitosana reticuladas foi classificado como adsorção física, possuindo calores de adsorção $(\Delta \mathrm{H})$ baixos (Tabela 1$)$.

A partir das constantes de Langmuir $\left(\mathrm{K}_{\mathrm{L}}\right)$ e da constante de Freundlich $\left(\mathrm{K}_{\mathrm{F}}\right)$, pode-se constatar que as esferas de quitosana e esferas de quitosana reticulada têm uma boa afinidade pelos íons de $\mathrm{Cu}(\mathrm{II})$. Porém, observase que a capacidade de adsorção das esferas de quitosana é maior que a das esferas de quitosana reticulada, pois o valor de qmax (capacidade máxima de adsorção) para as esferas de quitosana foi maior que para as esferas de quitosana reticulada (Tabela 1).

Tabela 1. Parâmetros de adsorção dos modelos matemáticos de Langmuir e Freundlich.

\begin{tabular}{|c|c|c|}
\hline Parâmetros & $\begin{array}{c}\text { Esferas de } \\
\text { quitosana }\end{array}$ & $\begin{array}{c}\text { Esferas de quitosana } \\
\text { reticulada }\end{array}$ \\
\hline qmáx (mg g-1) & 18,5 & 14,0 \\
\hline KL (Lmg-1) & 0,0960 & 0,0098 \\
\hline$\Delta \mathbf{H}$ (kJmol-1) & 2,520 & 0,746 \\
\hline $\mathbf{R}_{\mathbf{L}}$ & 0,094 & 0,500 \\
\hline $\mathbf{K}_{\mathbf{F}}(\mathbf{L g}-1)$ & 3,27 & 0,28 \\
\hline $\mathbf{n}$ & 2,5 & 1,4 \\
\hline
\end{tabular}

A quantidade máxima de íons de cobre(II) adsorvida para esse sistema foi de $18,50 \mathrm{mg}$ de cobre por grama de quitosana. Tal valor é, quando comparado com a literatura, razoavelmente elevado. Carvalho ${ }^{32}$ encontrou um valor de qmax, usando o modelo de Langmuir, de $5,9185 \mathrm{mg}$ de íons $\mathrm{Cu}(\mathrm{II})$ por grama de esfera de quitosana $(\mathrm{GD}=78 \%)$ e no mesmo trabalho encontrou $6,7317 \mathrm{mg}$ de íons $\mathrm{Cu}(\mathrm{II})$ por grama de esfera de quitosana com uma espécie de bactéria imobilizada. Ghaee et al. ${ }^{33}$ estudando a adsorção de íons cobre(II) em membranas de quitosana 
$(\mathrm{GD}=90 \%)$ de diferentes morfologias, encontraram um valor, ligeramente inferior ao encontrado nesse trabalho para esferas, de 17,660 $\mathrm{mg} \mathrm{g}^{-1}$ para a capacidade máxima de adsorção de membranas, contendo $6 \%$ de quitosana com aproximadamente $0,16 \mathrm{~mm}$ de espessura, sendo, os dados experimentais melhor ajustados pelo modelo isotérmico $\left(20^{\circ} \mathrm{C}\right)$ de Freundlich.

Patrulea et al..$^{34}$ estudaram isotermicamente a adsorção de íons cobre(II) em grânulos esféricos de quitosana $(75 \%<\mathrm{GD}<85 \%)$ e quitosana reticulada com glutaraldeído. Os autores encontraram valores de capacidade máxima de adsorção de $7,0025 \mathrm{mg} \mathrm{g}^{-1}$, para os grânulos de quitosana, e de $8,6720 \mathrm{mg} \mathrm{g}^{-1}$, para os grânulos de quitosana reticulada. Em ambos os casos, o modelo que melhor ajustou os dados experimentais foi o de Langmuir.

Feng et al. ${ }^{35}$ estudaram a adsorção de cobre(II) em microesferas de quitosana $(\mathrm{GD}=90 \%)$. A capacidade máxima de adsorção dada pelo modelo de Langmuir foi de $189,51 \mathrm{mg} \mathrm{g}^{-1}$, para as microesferas sem impressão de íons Cobre(II). A relação massa e área superficial foi estudada por Vieira e Beppu ${ }^{36}$, empregando adsorção de íons $\mathrm{Hg}(\mathrm{II})$ em esferas, microesferas e membranas de quitosana. Os estudos dinâmicos apresentaram maior adsorção dos íons em membranas do que em esferas, uma vez que a concentração de quitosana foi maior nas membranas (redução de $50 \%$ da massa inicial da solução). Já estudos estáticos favoreceram a adsorção em esferas devido ao maior tempo de contato. A área superficial influencia o processo de adsorção de tal forma que a diminuição da área superficial aumenta a quantidade adsorvida, pois facilita a difusão intrapartícula, visto que, a adsorção é limitada pela resistência a transferência de massa externa.

Outro ponto importante é a reticulação. A escolha do agente reticulante bem como a sua proporção têm primordial influência nas capacidades de adsorção da quitosana. Vários outros agentes reticulantes são utilizados na literatura. Assim, têm-se buscado reagentes que não reajam com os grupos amino. Vieira e $\mathrm{Beppu}^{37}$, estudaram a interação de íons $\mathrm{Hg}$ (II) com membrana de quitosana e de quitosana reticulada com glutaraldeído e epicloridrina. O polímero reticulado com glutaraldeído mostrou uma maior adsorção $\left(75,5 \mathrm{mg} \mathrm{g}^{-1}\right)$ de íons $\mathrm{Hg}$ (II) quando comparado aos outros compostos testados. Vasconcelos et al..$^{38}$ verificaram a adsorção de íons cobre(II) em quitosana reticulada com N-N'-[bis(2hidroxi-3-formil-5-metilbenzil-dimetil)]-etilenodiamina. Os resultados encontrados, utilizando isoterma de Langmuir, mostraram uma capacidade máxima de 113,6 $\mathrm{mgg}^{-1}$ para íons $\mathrm{Cu}(\mathrm{II})$.

$\mathrm{O}$ valor obtido para o calor de adsorção de íons $\mathrm{Cu}(\mathrm{II})$ pelas esferas de quitosana foi de $2,52 \mathrm{kJmol}^{-1}$, caracterizando uma adsorção física (baixos calores de adsorção) ou fisiossorção. O valor obtido para o calor de adsorção de íons $\mathrm{Cu}(\mathrm{II})$, pelas esferas de quitosana reticulada, foi de $0,746 \mathrm{kJmol}^{-1}$, caracterizando uma adsorção física ou fisiossorção, devido ao baixo calor de adsorção.

\section{Considerações Finais}

Um estudo comparativo foi realizado, relacionando a adsorção de íons $\mathrm{Cu}(\mathrm{II})$ em soluções aquosas de concentrações de $20 \mathrm{mg} . \mathrm{L}^{-1}$ até $100 \mathrm{mg} . \mathrm{L}^{-1} \mathrm{em}$ esferas de quitosana e esferas de quitosana reticulada com glutaraldeído. Os resultados obtidos são compatíveis a outros trabalhos reportados. Fica evidente que as esferas de quitosana e de quitosana reticulada são eficientes na remoção de íons cobre(II), principalmente, a concentrações baixas, existindo, assim, uma influência da concentração inicial de íons cobre(II) na capacidade de adsorção dos materiais testados. Nas condições testadas, essa adsorção não é restrita a uma camada (monocamada) de adsorção, uma vez que os dados são melhores ajustados isotermicamente pelo modelo de Freundlich que pressupõe adsorção em superfície heterogênea. Também se conclui que o processo de adsorção é favorável.

\section{Referências}

1. Tavares, M. T.; Quintelas, C.;Silva, I. S.Problemas ambientais com soluções catalíticas.Madrid, Cyted,1998, 231-234.

2. Quintelas, C. M. C. Recuperação e Reutilização de Metais Pesados. 2000. 107f. Dissertação (Mestrado em Biotecnologia) Universidade do Minho, Braga-Portugal, 2000.

3. Li, N.; Bai, R. Sep. Purif. Technol.,2005, 42, 237-247.

4. Rangel-Mendez, J.R.; Monroy-Zepeda, R.; Leyva-Ramos, E.; Diaz-Flores, P.E.; Shirai, K. J. Hazard. Mater.,2009, 162, 503-511.

5. Popuri, S.R.; Vijaya, Y.; Boddu, V.M.; Abburi, K. Bioresour. Technol., 2009, 100, 194-199. 
6. Roberts, G.A.F. Chitin Chemistry. London, Ed. The Macmillan Press LTD, 1992, p. 1-349.

7. Muzzarelli, R.A.A. Chitin.New York:Pergamon Press, 1977, p. $1-4$.

8. Muzzarelli, R.A.A.; Tanfani, F.; Emanuelli, M.; Gentile, S.J. Appl. Biochem.,1980, 2, 380-3899.

9. Muzzarelli, R.A.A. Carbohydr. Polym.,2011, 84, 54-63.

10. Copello, G.J.; Varela, F.; Vivot, R.M.; Díaz, L.E. Bioresour. Technol.,2008, 99, 6538-6544.

11. Stopa, L.C.B. Quitosana Magnética para Remoção de Urânio (VI). 2007. 85f. Dissertação (Mestrado) - Instituto de Pesquisas Energéticas e Nucleares - Universidade de São Paulo, São Paulo, 2007.

12. Vieira, R.S.; Beppu, M.M. Colloids Surf., A, 2006, 279, 196-207.

13. Shafaei, A.; Ashtiani, F.Z.; Kaghazchi, T.Chem. Eng. J.,2007, 133, 311-316.

14. Anirudhan, T.S.; Rijith, S.; Tharun, A.R. Colloids Surf., A, 2010, $368,13-22$.

15. Jayakumar, R., Prabaharan, M., Muzzarelli, R.A.A. Chitosan for Biomaterials II.Berlin. Editora Springer. 2011, p. 1-22.

16. Beppu, M.M.; Arruda, E.J.; Santana, C.C. Polim.: Cienc. Tecnol.,1999, 163-169.

17. Yoshioka, S.A.; Braile, D.M.; Ramirez, V.; Goissis, G. Polim.: Cienc. Tecnol.,1995, 39-47.

18. Peniche, C.; Argüelles-Monal, W.; F. M. Goycoolea, F.M. Monomers, Polym.Compos. Renewable Resour.,2008, 517-542.

19. Rinaudo, M. Prog. Polym. Sci.,2006, 31, 603-632.

20. Atkins P., De Paula J.Físico-química. Rio de Janeiro-RJ. Editora LTC, 8.ed. v. 2, 2008, p. 322-330.

21. Castellan, G. Fundamentos de Físico-química. Rio de Janeiro-RJ. Editora LTC. 1.ed, 1986, p. 460-463.

22. Signini, R.; Campana Filho, S.P. Polim.: Cienc. Tecnol.,1998, 8(4), 63-68.

23. SIGNINI, R.; CAMPANA FILHO, S.P. Polim.: Cienc. Tecnol.,2001, 11(2), 58-64.

24. Morita, T.; Assumpção, R.M.V. Manual de Soluções, Reagentes e Solventes: Padronização, Preparação e Purificação. Ed. Edgard BlücherLtda, São Paulo, SP, 1995, 627p.

25. Mi, F.L.; Kuan, C.Y.; Shyu, S.S.; Lee, S.T.; Chang, S.F.Carbohydr. Polym.,2000, 41, 389-396.

26. Silverstein, R.M.; Bassler, G.C.; Morrill, T.C. Identificação espectrométrica de compostos orgânicos. Rio de Janeiro: Guanabara Dois, 1994.

27. Goy, R.C., Assis, O.B.G., Campana-Filho, S.P. Biotecnol. Cienc. Desenvolvimento, 2004, 33, 30-34.

28. Koyama, Y.; Taniguchi, A. J. Appl. Polym.Sci.,1986, 31, 19511954.
29. Fungaro, D.A.; Da Silva, M. G. Quim. Nova,2002, 25(6B), 10811085.

30. Soares, J.L. Remoção de Corantes Têxteis por Adsorção em Carvão Mineral Ativado com Alto Teor de Cinzas.1998. 84f. Dissertação (Mestrado) - Universidade Federal de Santa Catarina, Florianópolis, 1998.

31. Chaves, T.F.; Queiroz, Z.F.; Sousa, D.N.R.; Girão, J.H.S.; Rodrigues, E.A. Quim. Nova, 2009, 32(6), 1378-1383.

32. Carvalho, T.V. Biomateriais à base de Quitosana de Camarão e Bactérias para Remoção de Metais Traços e Petróleo.2006. 98f. Dissertação (Mestrado) - Universidade Federal do Ceará, Fortaleza, 2006.

33. Ghaee, A.; Shariaty-Niassar, M.; Barzin, J.; Matsuura,T. Chem. Eng. J., 2010, 165, 45 -55.

34. Patrulea, V.; Negrulescu, A.; Mincea, M.M.; Pitulice, L.D.; Spiridon, O.B.; Ostafe, V. BioResources, 2013, 8(1), 1147-1165.

35. Feng, T.; Wang, J.; Zhang, F.; SHI, X. J. Appl. Polym. Sci., 2013, $128,3631-3638$.

36. Vieira, R.S.; Beppu, M.M. Water Res., 2006, 40, 1726-1734.

37. Vieira, R.S.; Beppu, M.M. Colloids and Surf., A.,2006, 279, 196-207.

38. Vasconcelos, H.L.; Camargo, T.P.; Gonçalves, N.S.; Neves, A.; Laranjeira, M.C.M.; Fávere, V.T. React. Funct. Polym.,2008, 68, 572-579.

\section{Anderson J. L. Catão \& Roberta Signini ${ }^{*}$}

Universidade Estadual de Goiás, Unidade Universitária de Ciências Exatas e Tecnológicas, Caixa Postal 459, CEP 75001-970, Anápolis/ GO.

E-mail: roberta.signini@ueg.br 
